\title{
ANARQUIA E CRÍTICA EM LYGIA PAPE
}

Vanessa Rosa Machado ${ }^{1}$

\section{Resumo}

A ainda pouco estudada trajetória da artista plástica Lygia Pape (1927-2004) pode revelar interessantes aspectos sobre as radicais transformações ocorridas nas últimas cinco décadas, período em que ela produziu. Embora parte de sua produção tenha sido voltada ao trabalho poético dos materiais, outra vertente despertou nosso maior interesse: a que se relaciona ao tratamento das questões exteriores, de fora, do cotidiano e da cidade. Sua obra foi marcada pelo experirnentalisrno e pelo engajamento; como artista concreta e neoconcreta esteve envolvida no amplo "projeto cultural moderno", de reconstrução do país em outras bases. Tal engajamento assumiu outras formas no final dos anos 1960, período de recrudescimento das medidas ditatoriais, e se traduziu em obras participativas realizadas em espaços alternativos. Entretanto, e apesar da dura realidade, a grande maioria de suas propostas foge do tom sisudo da denúncia panfletária e da crítica direta. Trabalhos como "Ovo" (1968) e "Divisor" (1968), embora possam ser lidos numa vertente política, apresentam essa questão de modo indireto, filtrado esteticamente. Obras posteriores, de meados da década de 1970, como seu projeto "Eat me: a gula ou a luxúria?" (1976), sobre a transformação da mulher em objeto sexual, já incorporam questões ligadas à cultura de massa e à indústria cultural. Seus anárquicos filmes em super-8, que ora criam uma realidade distinta, ora registram poeticamente a realidade, se apóiam no humor, na insolência e no grotesco para trazer à tona espinhosos aspectos contemporâneos, como o domínio da imagem e a agonia do espaço público. Nesse trabalho pretendemos investigar as inusitadas formas assumidas pela crítica no trabalho de Lygia Pape, uma vez que diante de um contexto repressivo, humor e anarquia podem ter assumido o papel de abrir uma possibilidade para trazer ao debate, através da arte, as questões mais candentes daquele período.

Palavras-chave: Lygia Pape. Artes visuais. Crítica.

\begin{abstract}
The trajectory of the artist Lygia Pape (1927-2004) isn't until now extensively studied and can reveal interesting aspects about the drastic transformations of the last five decades, period when she produced. Although a fraction of her production is related to the poetics of the materials, another part, the one that motivated us, is related to exterior questions, to the daily live and to the city. Her work was marked by experimentation and engagement; as a concrete and neoconcrete artist was involved with the vast "modern cultural project", the reconstruction of the country upon other bases. This engagement assumed others forms during the last years of the sixties, period of hardened acts from the military dictatorship, and was traduced into participative pieces realized in alternatives spaces. However, and despite of the hard reality, most of her purposes are distant of a serious way of denounce and direct criticism. Works like "Ovo" (1968) and "Divisor" (1968), while can have a politic aspect, show this question in an indirect way, with an aesthetical filter. Posterior pieces, from mid seventies, like her project "Eat me: a gula ou a luxúria?" (1976), about the transformations of the woman into sexual object, already add aspects of mass culture and cultural industry. Her anarchic film made in super-8, that sometimes creates a distinct reality and other times registers poetically the reality, uses the humor, insolence and the grotesque to highlight some contemporary severe aspects, like
\end{abstract}

\footnotetext{
1 Mestre em Teoria e História da Arquitetura e do Urbanismo pelo Departamento de Arquitetura e Urbanismo da Escola de Engenharia de São Carlos - Universidade de São Paulo.
} 
image domain and the agony of public space. In this paper we analyze the uneven criticism forms on Lygia Pape's works, once inside a repressive context, humor and anarchism may have assumed the role of opening a possibility to bring to debate, through art, more candent questions of that period.

Key-words: Lygia Pape. Visual art. Criticism.

Em certa ocasião, a artista Lygia Pape (1927-2004) definiu-se como "intrinsecamente anarquista" (PAPE, 1998, p. 74-75), dona de uma vontade terrível de não respeitar as estruturas rígidas. Talvez essa intolerância a "poder e hierarquias" tenha conduzido sua trajetória, tão heterogênea. Tendo produzido desde os anos 1950, sua obra passou por diversas linguagens e suportes, dos trabalhos com a forma "livro" e das xilogravuras do período concreto e neoconcreto às instalações e filmes mais contemporâneos, passando ainda por trabalhos extra-artísticos, como o design e o ensino em universidades. Porém, unia essa diversidade de atuações uma postura permanentemente experimental.

Lygia tinha um método próprio de trabalho e não trabalhava inicialmente a partir de uma linguagem determinada. O método consistia em elaborar mentalmente o problema até atingir uma solução formal e, depois, com a questão solucionada esteticamente, executar a obra. Lygia definiu seu trabalho como algo de forma circular, a transitar entre uma a outra linguagem. Chegou a declarar que a arte era sua forma de conhecimento do mundo, ou seja, a maneira com que conseguia se relacionar, entender, questionar o mundo à sua volta. Seus trabalhos eram acompanhados de forte carga conceitual; Lygia era graduada e mestre em Filosofia.

Podemos dizer que parte de sua produção esteve ligada ao trabalho com as possibilidades poéticas dos materiais, como "Tetéias" (1979-1991), "Amazoninos" (19891992) e "Windbow" (1979), e que outra parte, a qual nos voltaremos, trata predominantemente de questões exteriores ao campo das artes plásticas, questões mais relacionadas ao ambiente social, cultural e urbano em que Pape produziu e também à industria cultural e à cultura de massas.

O presente artigo intenciona discutir o sentido de crítica em parte da produção de Lygia Pape e apontar suas particularidades.

Em sua dissertação de mestrado Lygia defendeu que durante o Neoconcretismo os artistas mantiveram um posicionamento político que não se fazia num nível imediato, mas que seria, nas palavras da artista, "fruto de um trabalho, diríamos, indireto, revolucionário porque inventor" (PAPE, 1980, p. 42). Trabalho que encontrava uma resolução estética não-panfletária e distinta, portanto, daquela empreendida por artistas mais incisivos. Tal "caráter político indireto", "revolucionário porque inventor", norteou diversas experiências de Lygia que trataram dos aspectos mais espinhosos relacionados à realidade, inclusive durante o duro período da ditadura militar.

Se no primeiro período em que atuou como artista, durante o Concretismo e Neoconcretismo, esteve engajada num projeto idealista e positivo de reconstrução do mundo em outras bases, o "projeto cultural moderno", quando o golpe militar de 1964 impôs uma outra realidade, Lygia Pape, assim como outros artistas, redefiniu sua forma de trabalho, procurando inventar alternativas de atuação, dentro e fora do circuito da arte.

Nos primeiros momentos sua experimentação questionou as convenções e o local de sua prática (o circuito da arte), para em seguida, estender a indagação sobre o papel da arte para o conjunto dos discursos contemporâneos. 
$\mathrm{Na}$ exposição Nova Objetividade Brasileira, articulada por Hélio Oiticica no Museu de Arte Moderna do Rio de Janeiro (MAM-RJ) em 1967, Lygia deu a medida de sua atitude iconoclasta ao ironizar a arte "morta dos museus" colocando como seu contrapondo formigas vivas, incontroláveis. Pape mostrou duas "Caixas de humor negro": sua "Caixa das Baratas" apresentava, à maneira das caixas dos entomólogos, uma coleção de baratas mortas dispostas em uma malha geométrica numa caixa acrílica de fundo espelhado, que refletia os rostos dos visitantes por entre os insetos mortos.

Assim, pela aversão, conduzia uma crítica à instrumentalização das produções de arte pelas instituições ${ }^{2}$.

Já a "Caixa das Formigas" trabalhava uma dimensão mais erótica, de devoração da carne, e da imprevisibilidade das coisas vivas (as formigas chegavam a escapar pelos orifícios de respiração da caixa e subir pelas obras de outros artistas). Continha enormes saúvas que se agrupavam em torno de um pedaço de carne crua. No fundo da caixa, também espelhado, sobre uma série de círculos estava a frase "a gula ou a luxúria".

Importante frisar a maneira particular e paradoxal pela qual se concretizava. essa crítica institucional, não era nada raro que essa produção fosse acolhida pelos museus.

Arantes (1973, p.5) afirmou que "pode-se dizer que de 1965 a 1969 - até a revanche do regime - boa parte dos artistas pretendiam, ao fazer arte, estar fazendo política". Porém, nas obras de alguns artistas, entre eles Lygia Pape, essa resistência assumiu outras formas. Junto às obras diretamente políticas houve propostas que 'envolviam manifestações coletivas na cidade, obras "participativas" em espaços extra-artísticos.

Nesse sentido, no final dos anos 1960 e início dos 1970, iniciativas procuraram se dirigir a um público, por assim dizer, leigo, para transformá-la em público de arte, ou que, em outra medida, propuseram expandir o museu para os lugares públicos.

Um exemplo dessa nova postura foi a obra "Ovo" (1968), apresentada no evento coletivo "Apocalipopótese", organizado por Frederico Morais nos jardins do MAM-RJ. Os "Ovos" de Pape eram cubos com arestas de madeira de $80 \mathrm{~cm}$, cobertos por uma fina película de plástico azul, vermelho ou branco. As pessoas deveriam entrar dentro deles e "nascer", rompendo a "casca" num ato performático. "Uma proposição nítida e simples", segundo Pedrosa (2004), que colocava de uma forma poética a possibilidade de fazer surgir um mundo novo. Para Oiticica (1969) o "Ovo" significou uma "transformação universal entre o dentro e o fora", uma estrutura aberta, a criação de um limite construído para ser transposto.

Do mesmo ano foi o "Divisor", evento causado pela apropriação de um grande quadrado de tecido branco de 30 metros de lado, cheio de fendas dispostas de forma regular por onde se deveria colocar a cabeça, deixando o corpo envolvido pelo grande tecido, que unia todos os participantes.

Inicialmente a obra foi entregue às crianças de uma pequena favela vizinha à casa de Lygia, as quais imediatamente descobriram como a proposta deveria funcionar, colocando as cabeças por entre as fendas, como disse Lygia, "numa brincadeira fantástica" (PAPE, 2002).

Tratava-se de uma obra cujas significações eram encontradas pela experiência direta e fundadas num repertório alheio ao conhecimento formal e corrente das artes plásticas.

Retomando a mencionada fala de Lygia ao tratar do Neoconcretismo, o caráter

\footnotetext{
${ }^{2}$ Lygia, contestadora. chegou a apresentar a "Caixa das baratas" quando o MAM-R.I recebeu uma verba para a compra de obras, porém, como esperado, foi recusada.
} 
indiretamente político do "Divisor" relacionava-se ao destaque dado às cabeças, únicas partes do corpo que ficavam à mostra, assim, os participantes eram naturalmente impelidos a conversar, trocar idéias, refletir, e a enxergar o mundo por cima. Apontava, então, para a necessidade do entendimento e reflexão sobre a situação política e, ao mesmo tempo, evidenciava que essa não era uma tarefa solitária: via-se um grupo, um coletivo, procedendo da mesma maneira.

O ano de 1968 marcou um momento de inflexão na trajetória de Pape (e não só na dela, a bem da verdade). Os anos 1960 assinalaram um período particular, no Brasil e em todo o mundo, em que houve grande produção de intelectuais e artistas, em geral orientados pelo pensamento de esquerda. Surgiu também, nesse contexto, um renovado interesse da arte pela cidade, que tem origem tanto no projeto de encontrar novas formas de relacionamento entre arte e vida cotidiana, quanto, a exemplo da tomada do espaço público pelas manifestações contrárias à ditadura, na reivindicação da cidade como campo de reflexão e ação.

Experiências como "Ovo" ou "Divisor" norteavam-se pelo desejo de ampliar o alcance da experimentação estética. Um sentido transcendente, porque vislumbrava a transformação da subjetividade de cada participante; intencionava-se que a experiência modificasse a maneira de perceber a si mesmo e ao mundo.

Mas, enquanto tais trabalhos tinham uma solução formal indireta em relação à situação política (como proposições de participação), algumas obras de Pape do mesmo período e outras um pouco posteriores se desviaram intencionalmente para o sarcasmo e para a ironia.

Por exemplo, para provocar um som de choro e lamento, na "Caixa caveira q geme" (1968), Lygia usou o mecanismo de uma boneca que chorava para dar o sentido de sofrimento que a caixa emitia ao ser sacudida, gerando uma forma inusitada de comentar a dura situação política. Já no poema visual "Língua apunhalada" (1968), Lygia era fotografada mostrando a língua manchada de sangue, revelando de certa maneira, que se interessava menos por tomar uma posição panfletária que por ironizar, debochar, mostrar a língua pra aquilo tudo.

No período da ditadura militar Lygia Pape permaneceu no Brasil, apesar da repressão e da ida de vários artistas, inclusive de Lygia Clark e de Hélio Oiticica, para o exterior. Sofreu graves sanções, chegando a ser presa e torturada ${ }^{3}$. Apesar dessa experiência decidiu permanecer no país e em sua produção intensificaram-se os contornos do humor e da ironia. Nesse período, Lygia manteve o caráter experimental de seus trabalhos, porém sua atuação tendeu a ser crescente mente "marginal" em relação ao circuito de arte, o que se revela de modo particular em seus filmes realizados em super- $8^{4}$, que criavam, segundo

\footnotetext{
${ }^{3}$ Em depoimentos e entrevistas, Lygia Pape assumia que havia passado por experiências bem duras e indicava que havia sido penalizada: "sou uma das raras artistas plásticas que participaram desse período, no sentido físico da coisa. Eu realmente sofri, mas atualmente só quero falar disso no sentido de liberdade" (PAPE, 1998, p.77). Somente em 2003, a Denise Mattar, revelou claramente que havia sido presa e torturada. Lygia não se filiara a nenhum partido ou organização política, mas tinha "idéias de solidariedade e generosidade", próximas às do "chamado antigo socialismo" (PAPE, 1998, p.78).

${ }^{4}$ O super-8 se popularizou na década de 1970 devido a sua leveza, maleabilidade e facilidades técnicas. Segundo Machado .Ir. (2003). as imperfeições próprias da bitola, como tremidos e desfoques, foram utilizadas por artistas, arquitetos e poetas como proposição estética, o que agregava às produções um caráter marginal, estendido aos lugares alternativos da exibição. No período. Pape fez 6 curtas metragens em super-S, entre eles um filme sobre um "Ovo" (1970, em cores, 20 min), "Arenas calientes" (1974, em cores, 20 min), "Wampirou" (1974, em cores. 20 min), "Carnival in Rio" (1974, em cores, 20 min), "Our parents' (1974, em cores, I 0 min) e "Favela da Maré" (1982, em cores, $10 \mathrm{~min}$ ).
} 
Machado Jr. (2003), um "contraponto dissonante e irônico" em relação ao cinema convencional.

Alguns desses filmes criavam situações descoladas da vida cotidiana, inventavam com doses de humor uma "nova realidade" disparatada onde referências à cultura erudita apareciam mescladas a toda sorte de elementos da indústria cultural, como ocorre em "Wampirou" (1974), filme que mostra o cotidiano de um vampiro artista mais adaptado à vida diurna urbana da classe média que aos terrores e excentricidades de uma vida de vampiro. Wamp lê gibis, assiste a desenhos animados pela TV, ouve Jimmy Rendrix e toma Coca-cola de canudinho. Como um artista, ele se depara com o mercado de arte representado por um marchand que lhe rouba até a identidade, e, como um transeunte comum passeia pela cidade, retratada constantemente em ruínas ou com portas fechadas.

"Wampirou" ao apropriar-se da figura de um vampiro recorre ao universo do grotesco. Lygia refaz um personagem que permeia o imaginário das criaturas noturnas aterrorizantes para imprimir-lhe características que funcionam como contrapontos, resultando num vampiro tropical de vida diurna. As cenas vampirescas, que num filme de terror serviriam para assustar os espectadores, no filme de Pape tornam-se caricaturas, que somadas à maquiagem, ao improviso das cenas e à própria linguagem adotada conferem uma atmosfera cômica, propositadamente ridícula.

Os filmes em super-8, como toda a produção de Pape, possuíam forte carga conceitual. Eram preenchidos por citações a uma tradição culta, onde além e apesar do absurdo da ficção não havia gratuidade: encontram-se nos filmes apontamentos críticos sobre nosso contexto político-cultural. No entanto, referências e críticas apareciam de trás do humor.

O cotidiano de Wamp era povoado por referências tais como a Coca-cola, os quadrinhos de super-heróis, o som de Jimmy Hendrix e o Pica-pau. A vida do vampiro não era em nada anormal: ele tinha uma vida diurna, passeava pela cidade e assistia à TV; um vampiro tão "normal" que estava sujeito à mesma avalanche consumista de produtos e comportamentos que então invadia a vida da classe média.

Igualmente relacionada ao mundo da mercadoria aparecia a arte. $\mathrm{O}$ filme era sarcástico ao retratar a relação entre o artista (Wamp) e o mercado de mie (marchand). A arte, como a Coca-cola, aparecia apenas na dimensão de mercadoria. Não aparecia mais, como nas obras anteriores, "Ovo" e "Divisar", como elemento de mudança.

Além disso, a cidade era representada como em ruínas ou como espaço fechado, sendo que as ações do filme transcorriam unicamente no espaço privado da casa.

Aspectos dessa nova cidade que se configurava, onde o capitalismo já impunha um outro tipo de experiência urbana, mediada pela publicidade e pela indústria cultural, aparecem de forma contundente no projeto "Eat me: a gula ou a luxúria?" (1976), obra decisiva na trajetória de Pape, que trouxe à tona questões ligadas à generalização do consumo, em suas dimensões mais vulgares. Esse projeto englobou duas exposições (realizadas em São Paulo na galeria Arte Global e no Rio de Janeiro no MAM) e um filme "Eat me" em $16 \mathrm{~mm}$. Segundo a artista, o projeto era uma crítica ao rebaixamento da mulher à condição de objeto de consumo.

O filme "Eat me" (1975) confundia os sentidos do espectador através de imagens em cores vibrantes que remetiam ao estereotipo da pornografia: uma boca feminina e uma 
masculina que, lembrando ambas uma vagina, chupavam e expeliam objetos.

O filme era o resultado do encadeamento de uma seqüência que se alternava entre uma boca masculina sensual, com bigode e barba, que chupava um objeto parecido com uma pedra e uma boca feminina com batom vermelho chupando uma salsicha com mostarda. O som que acompanhava a seqüência era de gemidos sexuais femininos que iam aumentando de volume a acabavam num grito. A "montagem matemática" usada par Pape ia acelerando crescente mente o filme, num ritmo sexual, cujo orgasmo corresponderia à superposição dos planos das bocas. Porém, a possibilidade do clímax era frustrada pela narração abrupta do anúncio publicitário das "Conchas Cook". Ainda enquanto as bocas se alternavam, o anúncio invadia a trilha sonora: "caldo de feijão, feijão sem caldo, feijão com caldo, compre as Conchas Cook".

Lygia trabalhou com imagens próximas da linguagem da propaganda, que se vale de apelos visuais para arrebatar o consumidor. Evidenciava nossa exposição constante aos recursos da comunicação de massa, em torno de um consumo que provoca os desejos, mas não os satisfaz.

Já na exposição realizada no MAM-RJ, vitrines e tendas, exibiam perucas e outros artefatos usados pela mulher para transformar-se em objeto de desejo, como seios, dentes e cílios postiços, que serviam para chamar a atenção a atos corriqueiros, lançando luz sobre o significado desses comportamentos. Lygia também expunha saquinhos com "objetos de sedução", batons, pêlos, calendários de mulher nua, loções afrodisíacas, que eram vendidos a um cruzeiro, o que, segundo a artista, era uma forma de contestar o mercado de arte: "as pessoas mais diversas compravam esses 'objetos de arte'. Eu carimbava, beijava, marcava de batom cada um deles, e assinava" (MATTAR, 2003, p. 84).

No exterior do museu foi projetado um filme com a imagem de Pape seduzindo por meio de gestos os possíveis visitantes da exposição. O filme funcionava como um outdoor e reproduzia nos gestos de Pape sua linguagem de apelo aos sentidos.

Em "Eat me: a gula ou a luxúria?", Lygia Pape descontextualizou na vitrine de um espaço de exposição um grupo de objetos que a mulher cotidianamente usa para ser desejada, definindo esses artigos como "instrumentos recolhidos do cotidiano e oferecidos ao uso de uma visão crítica, de deboche ou de acomodação" (MALASARTES, 1976, p.23). Esses "objetos de sedução" não seriam mais colocados como aparatos para o deleite e olhar masculinos, mas, na categoria de objetos de arte, evidenciariam seus significados ocultos. A partir de então, a atitude crítica (ou a do deboche) se tornaria possível.

Nesta breve análise procuramos mostrar como durante os diferentes períodos da produção de Lygia Pape seu engajamento nas questões da cidade e da vida cotidiana encontraram diversas soluções. Enquanto em obras como "Divisor" e "Ovo", emergia um intuito positivo de transformação do indivíduo e da cidade através da participação ativa do corpo, num período posterior, que podemos chamar mais contemporâneo, Lygia passou a captar aspectos da cidade real, situações já consolidadas onde a intervenção transformadora se tornara difícil, se não impossível. Obras como "Wampirou" e "Eat me: a gula ou a luxúria?" deixavam de enxergar na vida urbana possibilidades de conformação de ambientes mais transcendentes para trazer à tona outros discursos, mais afinados com uma realidade crua, num sentido mais duro e menos positivo.

Despontam nessas obras características de uma cidade desencantada, onde já se encontram os mais vulgares aspectos da indústria cultural e do capitalismo. No entanto, para tratar dessa dura realidade, da publicidade pornográfica, barracas de camelô, indústria cultural, do consumismo chegando à condição feminina, Lygia Pape utilizou recortes que, 
driblando discursos estereotipados, possibilitavam a apreensão crítica do cotidiano. Na medida em que as obras experimentavam linguagens renovadoras, revelavam faces inusitadas da experiência da cidade e instigavam à reflexão e a uma percepção mais atenta do mundo.

Ao mesmo tempo em que se distanciava do que pode ser entendido mais estritamente como "crítica", no sentido de uma forma direta ou moralizante de revelar situações, Lygia Pape, recuperando mais uma vez sua própria fala, através de uma elaboração estética de caráter "indiretamente político" dava nova forma à "crítica".

O que aqui definimos por crítica na produção de Lygia Pape se afina ao entendimento de que durante o período no qual houve um aumento da censura às manifestações de arte parece vir à tona uma atitude (que já se encontrava em latência em algumas obras anteriores de Pape, como nas "Caixas de humor negro") mais afinada ao anarquismo, à ironia, ao escracho, a qual identificamos como uma possibilidade encontrada em meio ao cerceamento das liberdades de expressão para evidenciar algumas situações não apenas políticas, mas também referentes, por exemplo, às transformações urbanas e ao avanço da indústria cultural. (Ainda que esse tipo de crítica tenha posteriormente, de forma ambígua, sido absorvida).

Essa maneira encontrada para configurar um campo de discussão e reflexão sobre as questões que considerava relevantes a coloca entre aquelas engajadas na permanente investigação sobre o atual lugar da arte.

\section{Referências}

ARTE EM REVISTA. Ano 5, número 7, agosto de 1973.

ARANTES, Otília Fiori; FAVARETTO, Celso; COSTA, Iná Camargo; ADDEO, Walter César (Orgs.). São Paulo: Centro de Estudos de Arte Contemporânea.

CATALOGUE RAISONNÉ HÉliO OITICICA. Textos originais de Hélio Oiticica e outros em mídia digital - versão preliminar. Rio de Janeiro: Projeto Hélio Oiticica, 2004. 3 CD-ROM.

MACHADO Jr., Rubens. A polis ironizada: sobre a dimensão política do experimentalismo superoitista. In: Golpe de 64, amarga memória. São Paulo: Centro Cultural São Paulo, 2003.

MALASARTES. Rio de Janeiro, Números 1, 2 e 3. Rio de Janeiro: Imprinta. Setembro de 1975/ junho de 1976.

MATTAR, Denise. Lygia Pape - Intrinsecamente Anarquista. Rio de Janeiro: Relume Dumará: Prefeitura, 2003.

MORAES, Angélica de. Trabalho combina estética e ação política. O Estado de São Paulo, São Paulo, 22 abr. 1995.

PAPE, Cristina. Trabalho vivo e renovador. Entrevista com Lygia Pape realizada em fev.-mar. de 2002.

(Jornal eletrônico) In: < http://www2.uerj.br/ labore/entrevistaJigia_meio.htm>. Acesso em 15 de julho de 2004.

PAPE, Lygia. Catiti catiti, na terra dos brasis. Dissertação (Mestrado). Universidade Federal do Rio de Janeiro, Rio de Janeiro, 1980. 

Aguilar, 1998.

PEDrosA, Vera. De Capélio a Guevarcália. Correio da Manhã, 10 ago. 1968. In: Catalogue... 2004. 